\title{
Estudo das propriedades de concretos com adição de fibras vegetais e de polipropileno para uso em paredes estruturais
}

\author{
Study of concrete properties with vegetal \\ and polypropylene fibers for use in \\ structural walls
}

\author{
Ana Paula Silva Nascentes Borges ${ }^{1}$, Leila Aparecida de Castro Motta ${ }^{1}$, \\ Eliane Bernardes Pinto ${ }^{2}$
}

\footnotetext{
${ }^{1}$ Universidade Federal de Uberlândia (UFU) - Faculdade de engenharia Civil, Programa de Pós-graduação em Engenharia Civil, Uberlândia, Minas Gerais, Brasil.

e-mail: anapaulanascentes@gmail.com, lacastro@ufu.br

${ }^{2}$ Universidade Federal de Uberlândia (UFU) - Faculdade de engenharia Civil, Uberlândia, Minas Gerais, Brasil. e-mail: lily_bernardes@hotmail.com
}

\section{RESUMO}

Estudou-se neste trabalho as propriedades de concretos com adição de fibras vegetais (sisal e rami) e de polipropileno para uso em paredes estruturais. Realizou-se uma comparação do desempenho do concreto com a adição de fibras vegetais e de fibra de polipropileno, a fim de se verificar a possível substituição. Foram avaliadas a retração por secagem restringida, pelo ensaio do anel, além das propriedades mecânicas (resistência à compressão, tração por compressão diametral e módulo de elasticidade) e físicas (massa específica, índice de vazios, absorção por imersão e por capilaridade). Os teores utilizados foram de $0,25 \%$ e $0,5 \%$ para as fibras vegetais e para a fibra de polipropileno o teor de $0,25 \%$. Em relação à retração restringida foi observado que a adição de $0,25 \%$ de fibras não resultou em incremento do desempenho comparado ao concreto sem adição de fibras. Porém a adição de $0,5 \%$ de fibras vegetais demonstrou resultados satisfatórios, sendo superiores ao concreto de referência. Foi constatado que as propriedades mecânicas dos concretos com adição de fibras, em geral inferiores ao concreto de referência, não sofreram grandes alterações, exceto para o concreto com o maior teor de rami, que não apresentou dispersão adequada das fibras. O concreto com 0,25 \% de rami apresentou a maior absorção e índice de vazios, dentre todos os concretos estudados. Em relação à absorção por capilaridade, os concretos com adição das fibras vegetais demonstraram melhor desempenho, ou seja, redução da absorção por capilaridade. Concluiu-se que é plausível a substituição da fibra de polipropileno pelas fibras vegetais, principalmente de sisal.

Palavras-chave: Propriedades do concreto; fibra de polipropileno; fibra de rami; fibra de sisal; retração por secagem restringida.

\section{ABSTRACT}

The properties with addition of vegetal fibers (sisal and ramie) and of polypropylene for use in structural walls was studied in this research. An evaluation of the performance of the concrete with an addition of vegetable fibers and of polypropylene fiber was carried out, to verify the possible displacement. Were evaluated, the shrinkage under restrained conditions by ring test, as well the mechanical properties (compressive strength, splitting tension and static modulus of elasticity) and physical properties (specific mass, voids, immersion and capillary absorption). The contents used were $0.25 \%$ and $0.5 \%$ for the vegetable fibers and for the polypropylene fiber or $0.25 \%$ content. In relation to the shrinkage under restrained conditions, it was observed that the addition of $0.25 \%$ of fibers did not result in an increase in performance compared to concrete without fiber addition, but the addition of $0.5 \%$ of vegetal fibers showed satisfactory results, being superior to the reference concrete. The mechanical properties of the concrete with fiber addition, generally lower than the reference concrete, did not undergo major changes, except for concrete with the highest ramie content, which did not present adequate fibers dispersion. The concrete with $0.25 \%$ ramie presented the highest absorption and voids, among all the concretes studied. In relation to the absorption by capillarity, the 
concretes with addition of the vegetal fibers demonstrated better performance, that is, reduction of the absorption by capillarity. It was concluded that the substitution of polypropylene fiber by vegetal fibers, especially sisal, is plausible.

Keywords: Concrete properties; polypropylene fiber; ramie fiber; sisal fiber; shrinkage under restrained conditions.

\section{INTRODUÇÃO}

A construção civil geralmente está associada à baixa produtividade, elevado desperdício, além do controle de qualidade insatisfatório. Assim, várias técnicas construtivas vêm sendo desenvolvidas com o intuito de reduzir algumas deficiências existentes nesse setor. Exemplos de modelos construtivos que podem ser considerados como uma evolução do modelo tradicional são: os pré-moldados que possuem como atributos o aumento da produtividade, diminuição do tempo de construção, além da redução de desperdícios e custos [1] e as paredes de concreto maciças moldadas no local, que proporcionam maior qualidade e produtividade em comparação com a alvenaria [2].

O sistema construtivo de paredes de concreto maciças moldadas no local vem sendo amplamente utilizado, inclusive para a construção de habitações de interesse social. A adesão crescente é consequência do mesmo ser um sistema construtivo racionalizado, que oferece as vantagens da produção em alta escala e sem perda de qualidade, possuindo condições técnicas e econômicas que atendem à demanda atual do mercado brasileiro da construção [3]. De acordo com pesquisa realizada com as principais construtoras que utilizam esse sistema, uma característica do concreto utilizado nesse sistema é a adição de fibras de polipropileno, adotada por $73 \%$ das construtoras pesquisadas, com a finalidade de reduzir as fissuras nas paredes [3]. A adição de fibras em pequenas frações, principalmente as de baixo módulo de elasticidade, nos compósitos cimentícios muitas vezes tem a finalidade de reduzir a fissuração devido à retração plástica [4].

As fibras naturais são utilizadas como reforço de materiais há milhares de anos, mas somente durante a segunda guerra mundial foi dada a devida atenção às fibras vegetais especificamente. Devido a diminuição da reserva de fibras de asbesto, a fibra celulósica começou a ser empregada em substituição parcial ou total, atuando como reforço em materiais cimentícios, e, posteriormente teve sua utilização mais difundida, quando descoberto os malefícios causados pela fibra de asbesto à saúde [5].

Embora com propriedades diferentes entre as classes existentes, podem ser enumeradas as principais vantagens de utilização das fibras vegetais [6]: baixa massa específica; maciez e abrasividade reduzida; são recicláveis, não tóxicas e biodegradáveis; baixo custo; estimulam empregos na zona rural; baixo consumo de energia na produção.

As fibras vegetais podem ser extraídas das folhas como a fibra de sisal; do talo ou tronco vegetal como as fibras de juta e rami; do caule como o bambu e a cana de açúcar e do fruto como a fibra de coco e algodão [7]. Neste trabalho foram utilizadas as fibras de sisal e de rami.

Verificou-se neste trabalho a possibilidade de substituição das fibras de polipropileno pela fibra vegetal, uma vez que atualmente a fibra de polipropileno é empregada nos concretos utilizados em paredes estruturais para habitações de interesse social. Justifica-se esse tema na semelhança e até superação das propriedades mecânicas das fibras de sisal e rami quando comparadas à fibra de polipropileno. Além disso tem-se um material de baixo custo, renovável, amplamente disponível e eficiente energeticamente. Ressalta-se que a durabilidade das fibras não foi investigada nem se constituiu em uma preocupação, considerando que a principal contribuição das fibras no atual estudo seria nas primeiras idades, ou seja, melhora do desempenho dos compósitos quanto à retração plástica, quando as fibras vegetais não sofreram nenhuma deterioração pela matriz.

Neste contexto, este trabalho teve como objetivo estudar a influência da adição das fibras vegetais (sisal e rami) nas propriedades e desempenho do concreto para aplicação em paredes estruturais de edificações. Os compósitos (concreto com adição de fibras) foram avaliados quanto eficiência das fibras no controle da retração restringida em concretos, além das características mecânicas (resistência à compressão uniaxial, tração e módulo de elasticidade) e físicas (absorção por imersão e capilaridade e massa específica). A partir dos resultados obtidos foram realizadas comparações do desempenho das fibras vegetais com a fibra de polipropileno estudando a viabilidade da substituição desta última pelas fibras vegetais.

\section{MATERIAIS E MÉTODOS}

Para realizar a comparação das propriedades e comportamento em relação à fissuração dos concretos sem adição de fibras (referência) e com adição de fibras vegetais (sisal e rami) e de polipropileno, foram produzi- 
dos concretos de um mesmo traço com diferentes teores de fibras. Os teores de fibras adotados foram de $0,25 \%$ e $0,5 \%$ em volume. A fibra de polipropileno foi utilizada somente no teor de $0,25 \%$, pois na tentativa de preparação do concreto com adição de $0,5 \%$ de fibras de polipropileno, mesmo com a dosagem máxima de aditivo, obteve-se um concreto extremamente seco sem utilização prática, por isso descartado da pesquisa.

Os compósitos foram avaliados no estado fresco quanto à trabalhabilidade a partir do abatimento do tronco de cone. Para se obter uma trabalhabilidade adequada foi adicionado aditivo com a função superplastificante até a obtenção de um abatimento satisfatório. Para as avaliações no estado endurecido foram moldados anéis para a análise da retração para os diferentes compósitos produzidos e foram moldados corpos de prova para a determinação da resistência à compressão, módulo de elasticidade, resistência à tração por compressão diametral, massa específica, índice de vazios, absorção de água por imersão e por capilaridade.

\subsection{Materiais utilizados}

Para a fabricação dos compósitos foram utilizadas as fibras de sisal, rami e polipropileno. A fibra de sisal foi escolhida por possuir propriedades mecânicas satisfatórias, ser abundante no Brasil e uma das fibras mais estudadas em compósitos cimentícios. A fibra de rami, embora pouco estudada em compósitos cimentícios, é uma fibra mais fina, o diâmetro se assemelha ao das fibras atualmente aplicadas pelo mercado em concretos destinados a paredes de edificações.

A fibra de polipropileno é a fibra com maior aplicação no mercado de concreto destinado às paredes de concreto. Na Tabela 1, estão descritas algumas propriedades das fibras utilizadas neste trabalho. Esta pesquisa dará continuidade aos estudos desenvolvidos com fibras vegetais no Laboratório de Estruturas e Construção Civil da Universidade Federal de Uberlândia, dessa forma a caracterização das fibras de sisal e rami empregadas já foram caracterizadas por outros autores.

Tabela 1: Propriedades das fibras utilizadas [8], [9], [10], [11].

\begin{tabular}{l|l|l|l|l}
\hline FIBRA & $\begin{array}{l}\text { DIÂMETRO } \\
(\boldsymbol{\mu m})\end{array}$ & $\begin{array}{l}\text { MASSA ESPECÍFI- } \\
\mathbf{C A}\left(\mathbf{g} / \mathbf{c m}^{3}\right)\end{array}$ & $\begin{array}{l}\text { MÓDULO DE ELAS- } \\
\text { TICIDADE (GPa) }\end{array}$ & $\begin{array}{l}\text { RESISTÊNCIA } \\
\text { TRAÇÃO }(\mathbf{M P a})\end{array}$ \\
\hline Sisal & 229,98 & 1,511 & 12,17 & 353,95 \\
\hline Rami & 40 & 1,49 & 14,25 & 241,87 \\
\hline Polipropileno & 18 & 0,91 & 3,00 & 300 \\
\hline
\end{tabular}

Na produção do concreto foi utilizado o cimento de alta resistência inicial (CP V ARI), que possui grande utilização no sistema de parede de concreto, pela necessidade de rápida desforma. Como agregado miúdo foram utilizadas areia fina $(20 \%)$ e areia média $(80 \%)$, retiradas na região do triângulo mineiro. O agregado graúdo utilizado foi pedra britada de rocha basalto, zona granulométrica 4,75/12,5, denominada comercialmente como brita 0 . Na Tabela 2 estão algumas características dos agregados utilizados nesta pesquisa. A massa específica do agregado miúdo foi determinada de acordo com a ABNT NBR NM 52:2009 [12] e do agregado graúdo de acordo com a ABNT NBR NM 53:2009 [13]. A dimensão máxima característica e o módulo de finura foram determinados de acordo com a ABNT NBR NM 248:2003 [14].

Tabela 2: Características dos agregados utilizados.

\begin{tabular}{l|l|l|l}
\hline CARACTERÍSTICAS & AREIA FINA & AREIA MÉDIA & BRITA \\
\hline Massa específica $\left(\mathrm{g} / \mathrm{cm}^{3}\right)$ & 2,59 & 2,67 & 2,91 \\
\hline Dimensão máxima característica $(\mathrm{mm})$ & 1,18 & 4,75 & 12,5 \\
\hline Módulo de finura & 1,46 & 2,66 & 5,77 \\
\hline
\end{tabular}

A água utilizada na produção dos concretos foi proveniente da rede de abastecimento público da cidade de Uberlândia-MG. O aditivo utilizado foi o MasterGlenium 3400 also Glenium 3400NV da BASF. De acordo com as informações técnicas, esse aditivo é denominado como um aditivo hiperplastificante, com um alto índice de redução de água. A Tabela 3 contém alguns dados técnicos contidos na ficha técnica do produto. 
Tabela 3: Dados técnicos do aditivo hiperplastificante utilizado [15].

\begin{tabular}{l|l}
\hline \multicolumn{2}{l}{ DADOS TÉCNICOS - GLENIUM } \\
\hline Aspecto & Líquido \\
\hline Cor & Castanho escuro \\
\hline Base química & Éter policarboxilico \\
\hline Densidade $\left(\mathrm{g} / \mathrm{cm}^{3}\right)$ & $1,000-1,200$ \\
\hline $\mathrm{pH}$ & $08-10$ \\
\hline Consumo $(\%$ s.m.c* $)$ & $0,2-1,0$ \\
\hline * ${ }_{\text {sobre a massa de cimento }}$
\end{tabular}

\subsection{Produção dos compósitos}

Dosou-se um concreto semelhante ao utilizado nos sistemas construtivos de paredes de concreto, com uma consistência mais fluida, de forma que a adição de fibras não causasse redução significativa da trabalhabilidade. $\mathrm{O}$ aditivo foi dosado para se obter a consistência desejada, até o limite sugerido pelo fabricante $(1,0 \%)$, quando necessário. Os consumos dos materiais para produção de um metro cúbico de concreto estão apresentados na Tabela 4.

Tabela 4: Consumo de materiais para um metro cúbico de concreto.

\begin{tabular}{l|l|l|l|l|l}
\hline $\begin{array}{l}\text { CIMENTO CP V } \\
(\mathbf{k g})\end{array}$ & $\begin{array}{l}\text { AREIA FINA } \\
\mathbf{( k g )}\end{array}$ & $\begin{array}{l}\text { AREIA MÉDIA } \\
\mathbf{( k g )}\end{array}$ & BRITA 0 $(\mathbf{k g})$ & ÁGUA (L) & ADITIVO \\
\hline 384,60 & 200 & 800 & 769,20 & 230,76 & Variável \\
\hline
\end{tabular}

Para a produção dos compósitos, primeiramente as fibras de sisal e rami foram cortadas em dimensões aproximadas de $15 \mathrm{~mm}$ de forma a se atingir um comprimento próximo da fibra de polipropileno (12 $\mathrm{mm})$. As fibras vegetais foram secas em estufa e pesadas nas quantidades adequadas para cada teor.

As fibras vegetais possuem elevada capacidade de absorção, Savastano Jr. [16] descreve que na fibra vegetal submersa em água por 15 minutos, ocorre pelo menos $60 \%$ da absorção total. Para que não ocorresse grande redução da água necessária para a plasticidade da mistura, previamente à mistura do concreto as fibras vegetais foram submersas por aproximadamente 15 minutos em água, após esse período foram retiradas e foi garantida a retirada do excesso de água para que não interferisse na relação a/c. As fibras utilizadas podem ser visualizadas na Figura 1.
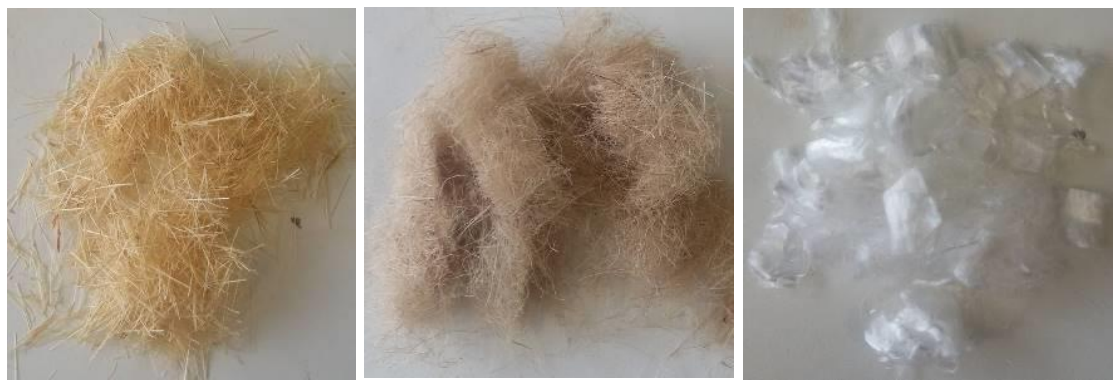

Figura 1: Fibras utilizadas na pesquisa (sisal, rami e polipropileno).

A ordem e tempo de mistura dos componentes do concreto foram definidos de modo a se obter uma maior dispersão dos materiais. A quantidade de aditivo utilizada foi definida em função do abatimento do tronco de cone (ensaio normatizado pela ABNT NBR NM 67:1998). Na Tabela 5 estão relacionados o teor de fibra, quantidade de aditivo, abatimento do tronco de cone e a nomenclatura adotada para cada um dos tipos de concretos produzidos. 
Tabela 5: Nomenclatura adotada, teor de fibra e aditivo e abatimento do tronco de cone.

\begin{tabular}{l|l|l|l|l}
\hline & NOMENCLATURA & TEOR DE FIBRA & TEOR DE ADITIVO* & ABATIMENTO (mm) \\
\hline \multirow{2}{*}{ Referência } & Ref & - & $0,4 \%$ & 187 \\
\hline \multirow{2}{*}{ Sisal } & $0,25 \mathrm{~S}$ & $0,25 \%$ & $0,6 \%$ & 170 \\
\cline { 2 - 5 } & $0,5 \mathrm{~S}$ & $0,50 \%$ & $1,0 \%$ & 123 \\
\hline \multirow{2}{*}{ Rami } & $0,25 \mathrm{R}$ & $0,25 \%$ & $1,0 \%$ & 185 \\
\cline { 2 - 5 } & $0,5 \mathrm{R}$ & $0,50 \%$ & $1,0 \%$ & 45 \\
\hline Polipropileno & $0,25 \mathrm{P}$ & $0,25 \%$ & $0,6 \%$ & 100 \\
\hline
\end{tabular}

*sobre a massa de cimento

Os compósitos foram moldados em corpos de prova cilíndricos de $10 \mathrm{~cm}$ de diâmetro e $20 \mathrm{~cm}$ de altura para avaliação das propriedades mecânicas (resistência à compressão, tração por compressão diametral e módulo de elasticidade) e físicas (massa específica, índice de vazios, absorção por imersão e por capilaridade). Em seguida à moldagem, os corpos de prova foram colocados em câmara úmida na qual permaneceram durante um período aproximado de 24 horas. Após esse período os corpos de prova foram desmoldados e dispostos em um tanque onde permaneceram submersos em água saturada com cal, até a idade de 28 dias, completado esse período os corpos de prova foram retirados do tanque. Também foram moldados anéis de concreto para a avaliação da retração por secagem restringida.

\subsection{Métodos de ensaio}

\subsubsection{Análise da retração por secagem restringida}

Os elementos de concreto quase sempre sofrem algum tipo de restrição, seja por atrito na base ou engastamento nas extremidades, isso geralmente ocorre devido a presença do aço da armadura e por deformações diferenciais que se desenvolvem entre a parte interna e externa do concreto [17]. O ensaio do anel tem grande importância para a análise de compostos cimentícios pois possibilita a reprodução do comportamento do concreto quando submetidos às restrições.

A avaliação da retração por secagem restringida baseou-se nas recomendações da ASTM C1581/C1581M - 16 Standard Test Method for Determining Age at Cracking and Induced Stress Characteristics of Mortar and concrete under Restrained Shrinkage. De forma simplificada o ensaio consiste em moldar o concreto ou argamassa ao redor de um anel de aço instrumentado com extensômetros e fazer a aquisição dos dados, nesse caso da deformação sofrida pelo anel até a data de fissuração do concreto ou até os 28 dias caso não ocorra a fissuração do mesmo. Na Figura 2 é apresentado o esquema do molde recomendado pela ASTM C1581 - 16 [18].
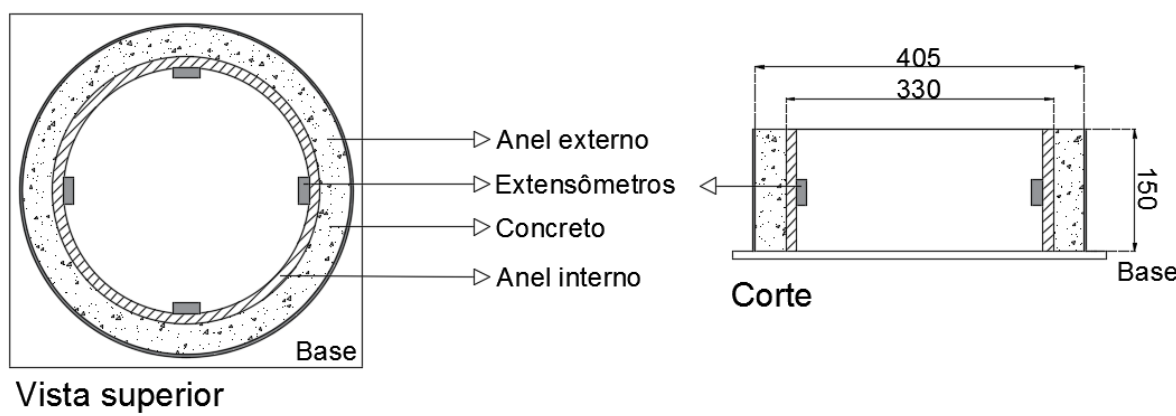

Figura 2: Esquema para o ensaio de retração restringida.

Foi realizada a instrumentação do anel de aço a partir da colagem de extensômetros elétricos, permitindo assim a avaliação da deformação do anel no decorrer do tempo. Em cada anel foram colados quatro extensômetros, em posições diametralmente opostas e na metade da altura do anel, conforme pode ser visualizado na Figura 2. A leitura da deformação no anel de aço foi realizada separadamente por cada um dos extensômetros, a ligação empregada foi em configuração de meia ponte com compensador. Foram utilizados 
compensadores de temperatura, chapas de aço com as mesmas propriedades e espessura do anel, as quais não foram submetidas à nenhuma força externa. Nessas chapas foram colados extensômetros em mesmo número dos utilizados nos anéis, dessa forma as deformações devido às variações de temperatura foram anuladas. Após a instrumentação e montagem os anéis foram armazenados em ambiente com temperatura controlada, onde permaneceram no decorrer do ensaio. O ensaio foi conduzido em sala com temperatura de $23 \pm 2{ }^{\circ} \mathrm{C}$ e umidade de $45 \pm 5 \%$.

A moldagem foi realizada em duas camadas de concreto aproximadamente iguais em cada anel, sendo que cada uma recebia 75 golpes com uma haste, além da vibração, com o intuito de consolidar a camada. É sugerido pela ASTM C1581-16 [18] que os anéis sejam moldados em cima de uma mesa vibratória, porém devido às dificuldades para o transporte do anel, os moldes foram adensados com vibrador mecânico de imersão. Após o preenchimento das duas camadas foi feito um acabamento de modo a nivelar a superfície do concreto.

O período de cura úmida ocorre nas primeiras 24 horas após a moldagem dos anéis, nesse período o molde foi coberto por um pano úmido e por um plástico. Ocorrida as 24 horas necessárias para a cura úmida, foram retirados o plástico e o pano para então ser realizada a retirada do anel externo. Assim como descrito na ASTM C1581-16 [18] após a retirada do anel externo foi feita a limpeza da parte superior do molde de concreto para proceder a selagem desse local com parafina. Esse procedimento é realizado com a finalidade da secagem ocorrer somente na superfície circunferencial externa conforme esquematizado e exemplificado na Figura 3. Uma vez finalizado o processo de selagem, iniciou-se a aquisição dos valores da deformação do anel de aço a cada dez minutos até a data de fissuração do concreto.

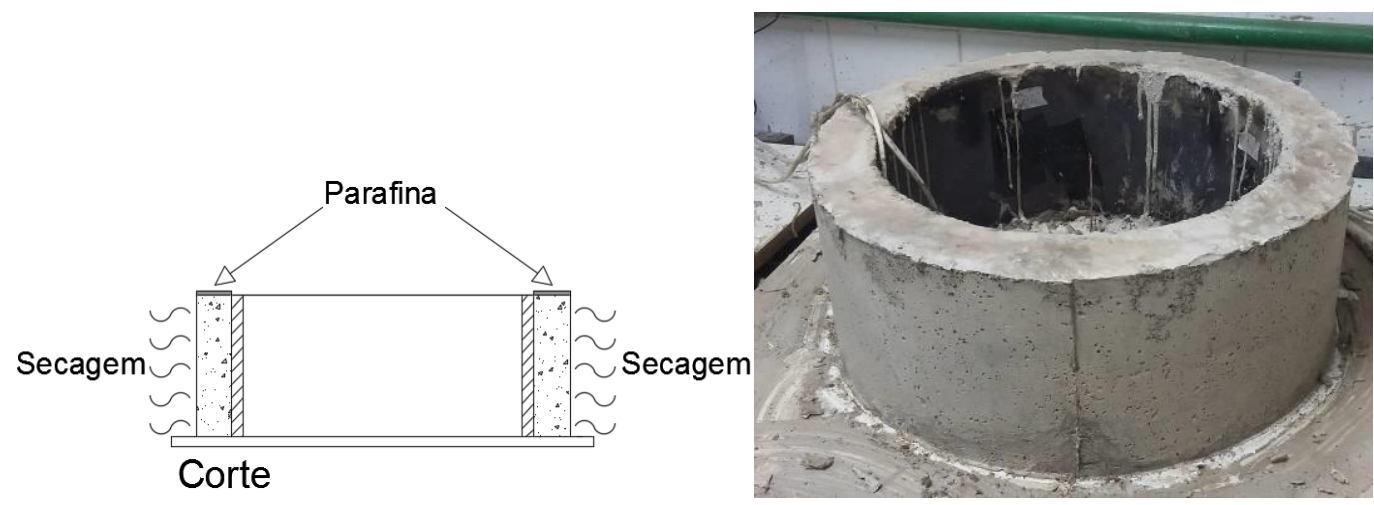

Figura 3: Esquema do processo de selagem e o corpo de prova com selagem finalizada submetido ao ensaio.

A idade de fissuração de acordo com a ASTM C1581-16 [18] é a idade a partir da moldagem até a súbita diminuição da deformação, essa diminuição pode ser evidenciada por um ou mais extensômetros. A diminuição é devido ao alívio de tensões gerado com a fissuração do anel de concreto. Uma vez ocorrido o alívio da tensão, geralmente em intervalo não maior que um dia, a partir de uma análise visual, uma ou mais fissuras, puderam ser encontradas próximas aos extensômetros que apresentaram as maiores variações, em todos os concretos estudados. Foram realizadas duas repetições para cada tipo de concreto, com exceção do concreto $0,25 \mathrm{R}$, em que será considerada apenas uma, pois não foi possível a determinação da idade de fissuração no outro ensaio realizado. Todos os resultados ficaram dentro do desvio de dois dias para um mesmo tipo de concreto, conforme recomendado na ASTM C1581-16 [18].

\subsubsection{Resistência à compressão e módulo de elasticidade}

O ensaio de resistência à compressão foi realizado de acordo com a ABNT NBR 5739:2007 [19] e para o módulo de elasticidade foi utilizada como referência a ABNT NBR 8522:2008 [20]. Os ensaios foram realizados em uma máquina universal de ensaios marca EMIC, modelo DL60000. Para a compressão uniaxial foram ensaiados cinco corpos de prova na idade de 28 dias, e para o módulo de elasticidade foram ensaiados três corpos de prova para cada tipo de concreto apenas aos 28 dias.

\subsubsection{Resistência à tração por compressão diametral}

O ensaio para verificação da resistência à tração por compressão diametral de corpos de prova cilíndricos de concreto foi realizado segundo os critérios da ABNT NBR 7222:2011[21]. Para esse ensaio foram utilizados 
três corpos de prova cilíndricos, aos 28 dias de idade do concreto. Os ensaios foram realizados na máquina universal de ensaios marca EMIC, modelo DL60000.

\subsubsection{Massa específica e absorção de água por imersão}

O ensaio para a obtenção da massa específica e absorção de água por imersão do concreto no estado endurecido foi realizado de acordo com a ABNT NBR 9778:2005 [22]. Ainda de acordo com essa norma, foi calculado o índice de vazios por imersão e fervura. Para a realização desse ensaio foram utilizadas duas amostras de cada tipo de concreto.

\subsubsection{Absorção de água por capilaridade}

O ensaio para a determinação da absorção por capilaridade foi realizado de acordo com a ABNT NBR 9779:2012 [23], em três corpos de prova cilíndricos.

\section{RESULTADOS E DISCUSSÃO}

\subsection{Retração por secagem restringida}

A seguir são apresentadas, para cada formulação estudada, as deformações típicas obtidas de dois extensômetros diametralmente opostos, como a norma sugere que seja feita a análise, em $\mu \mathrm{m} / \mathrm{m}$ e a idade do concreto em dias. As alterações momentâneas registradas pelos extensômetros devem-se à ruídos causados por interferência no ambiente, como o acendimento de lâmpadas, funcionamento de motores, entre outros. Por não ser objetivo deste trabalho o estudo do comportamento do concreto quanto às deformações internas causadas pelo calor de hidratação, os dados relativos ao primeiro dia foram descartados.

Na Figura 4 pode ser observado o gráfico obtido em um dos ensaios realizados com o concreto de referência.

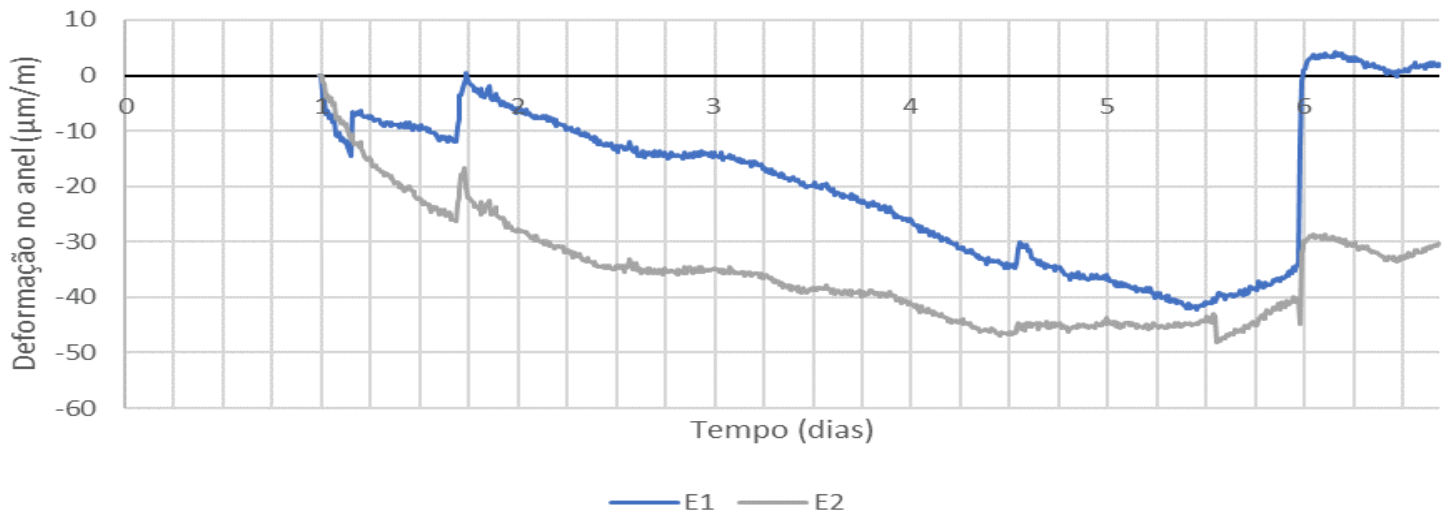

Figura 4: Deformação do anel de aço para o concreto de referência.

A fissuração deste concreto ocorreu após 143 horas da moldagem, próximo ao sexto dia de idade do concreto. A mudança repentina na deformação corresponde a idade da fissuração visível na amostra [24]. Pode-se perceber que os extensômetros não reproduzem a fissura da mesma forma, uma vez que quanto mais próximo à fissura, maior a diminuição da deformação registrada pelo extensômetro. Salienta-se também que no concreto sem adição de fibras, as fissuras quando se tornavam visíveis, praticamente ocorriam em duas posições diametralmente opostas. Ressalta-se que por falta de equipamentos adequados, como por exemplo luz fluorescente, para ajudar na identificação das fissuras, não se tem como objetivo deste trabalho numerar a quantidade de fissuras existentes no anel, uma vez que alguns concretos apresentavam fissuras tão finas que eram de difícil visualização, mesmo com lupa.

Na Figura 5 estão os resultados obtidos com o concreto $0,25 \mathrm{~S}$. 


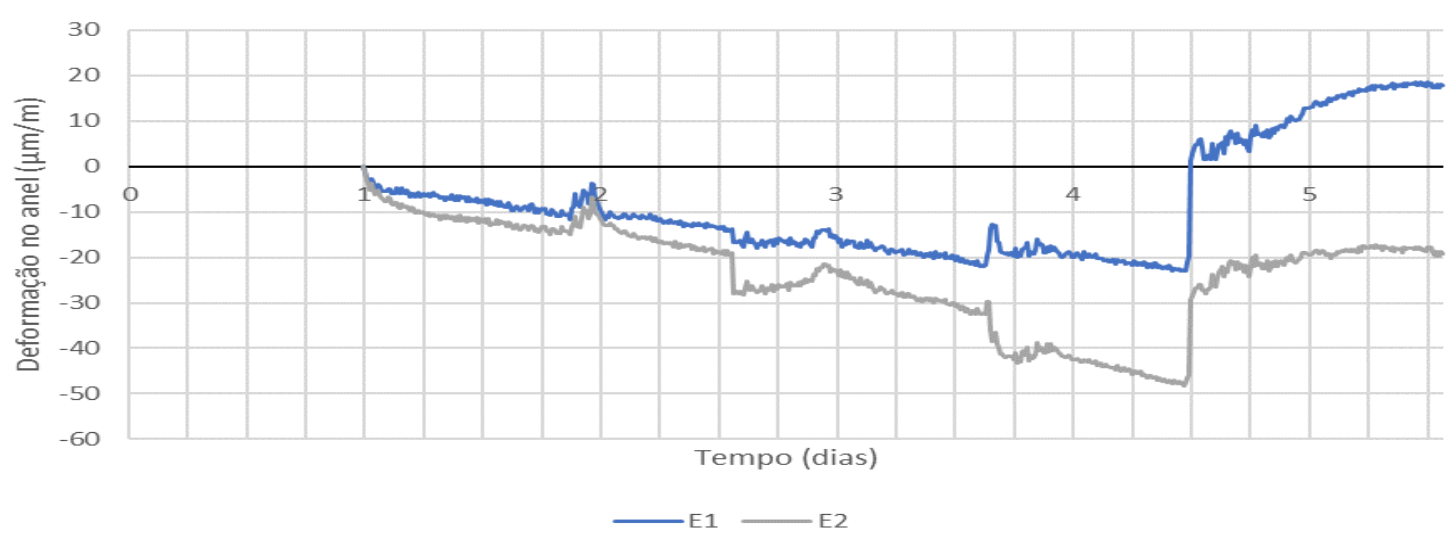

Figura 5: Deformação do anel de aço para o concreto 0,25S.

A fissura para esta amostra ocorreu após 107,5 horas após a moldagem do anel, aproximadamente aos 4,5 dias. Pode-se perceber também neste gráfico as possíveis interferências do ambiente como descrito anteriormente, pelos ruídos externos gerados.

Na Figura 6 estão os dados relativos ao ensaio realizado com o concreto 0,25R.

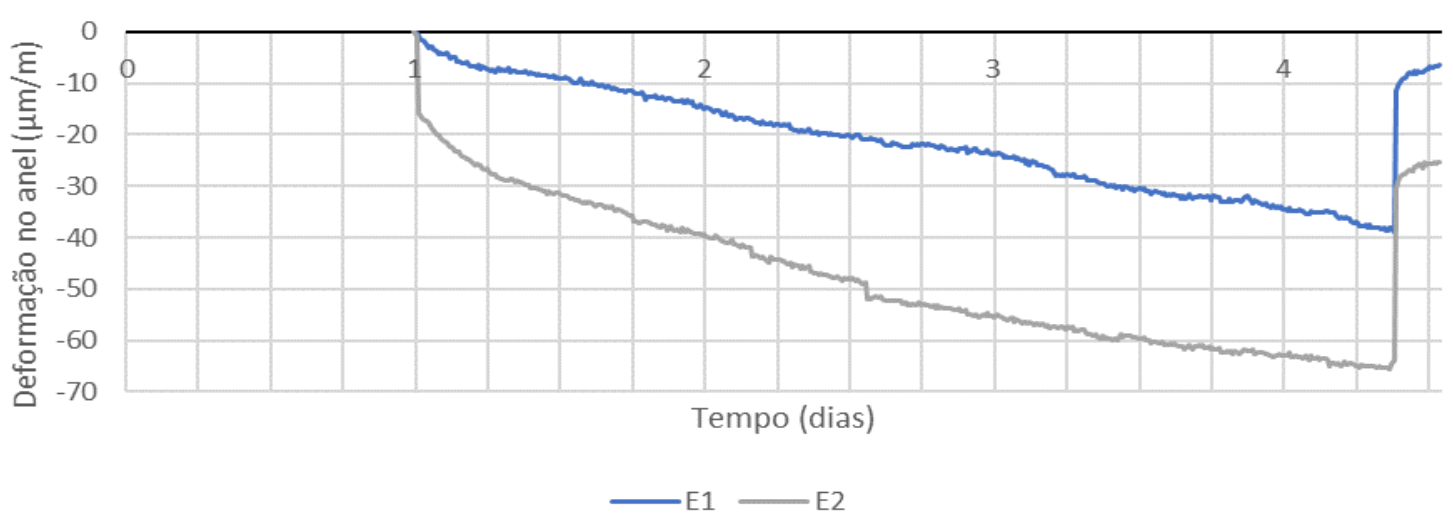

Figura 6: Deformação do anel de aço para o concreto $0,25 R$.

O concreto 0,25R apresentou a fissuração após 105 horas da moldagem, ou seja, próxima aos 4,5 dias. Em relação ao concreto 0,25P, na Figura 7 estão os resultados da deformação em função do tempo.

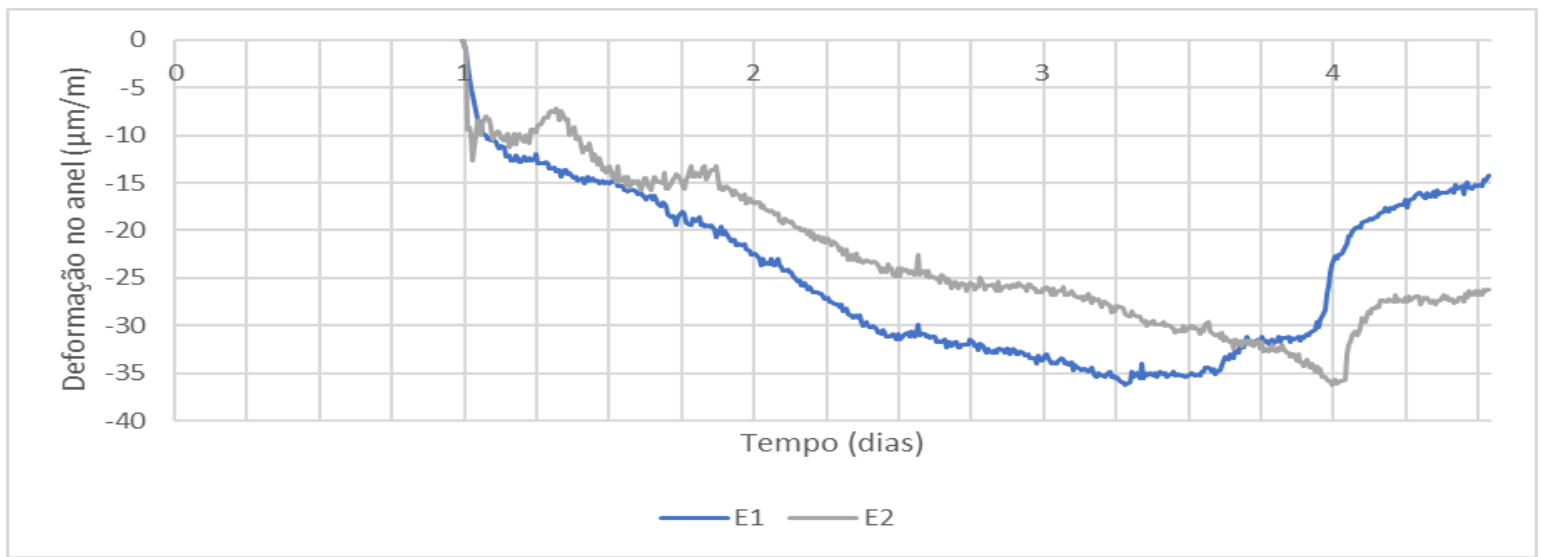

Figura 7: Deformação do anel de aço para o concreto 0,25P. 
Como pode ser visualizado a fissura para o concreto $0,25 \mathrm{P}$ ocorreu após 86,33 horas da moldagem, sendo aproximadamente 3,6 dias. O concreto 0,25P apresentou comportamento diferente dos concretos já apresentados (referência, 0,25S e 0,25R), uma vez que o alívio na deformação do anel não ocorreu simultaneamente nos dois extensômetros, ocorrendo primeiramente no extensômetro E1, destaca-se também que nesse extensômetro a queda não ocorreu de forma instantânea, mas pode-se observar duas reduções na deformação. Shah e Weiss [24] já haviam verificado esse comportamento para compósitos com frações volumétricas de fibras elevadas. Segundo os autores esses materiais apresentam primeiramente um alívio na deformação muito menos substancial e posteriormente outra diminuição também pouco substancial na deformação do anel no momento da fissuração visível. Ainda de acordo com os mesmos autores nas amostras com volumes elevados de fibras a deformação não diminui rapidamente, provavelmente devido ao fato de as fibras ajudarem a transferência de tensão através das microfissuras que se desenvolvem devido à restrição. Neste caso o desenvolvimento semi-estável da fissura na amostra é "preso" pelo reforço da fibra [24].

Foram dispostos na Figura 8 os dados relativos a deformação do anel de aço relativo ao concreto $0,5 \mathrm{~S}$.

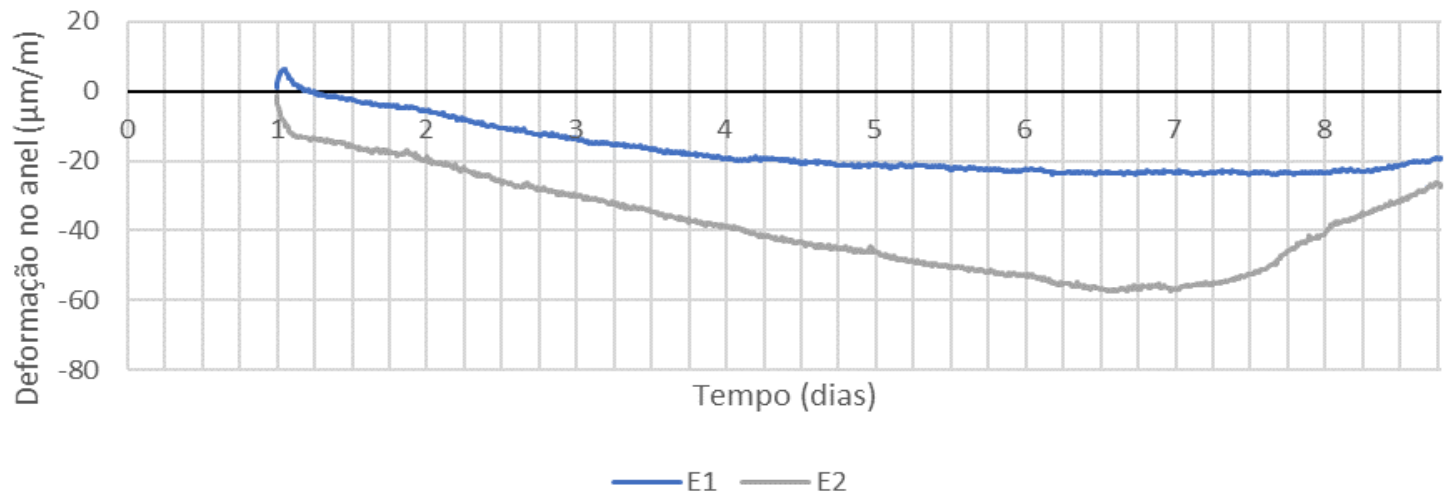

Figura 8: Deformação do anel de aço para o concreto 0,5S.

Observou-se que a fissura nesse anel apresentou comportamento diferente dos demais, provavelmente devido à maior quantidade de fibras "costurando" a fissura. De acordo com Shah e Weiss [24] em ensaios contendo elevado volume de fibras, a idade da fissura é de difícil determinação, uma vez que as fissuras se unem impedindo a propagação. O salto não ocorreu de forma brusca, mas sim de forma gradual como pode ser observado no extensômetro E2, tomado como referência para a determinação da idade de fissuração. Pôde ser confirmada a ocorrência da fissura uma vez que esta se tornou visível cerca de 24 horas depois. Devido a dificuldades na determinação do momento de fissuração do concreto, autores como Shah e Weiss [24] utilizaram, como forma de complementar os resultados obtidos no ensaio do anel, medições de emissões acústicas para a indicação de ocorrência de fissuras, principalmente em concretos com elevados teores de fibra.

Na Figura 8 nota-se também que o extensômetro oposto praticamente não sofreu alterações devido à fissura, observou-se nos concretos com $0,5 \%$ de fibras que as fissuras não ocorreram de forma diametralmente oposta, após o salto nos extensômetros apenas uma fissura foi encontrada nesses tipos de concreto. Pela diferença no comportamento, considerou-se que o momento de fissuração teve início quando iniciou o alívio da tensão no anel, cerca de 168,33 horas após a moldagem, no sétimo dia aproximadamente.

Na Figura 9 são demonstrados os valores de deformação encontrados para o concreto $0,5 R$. 


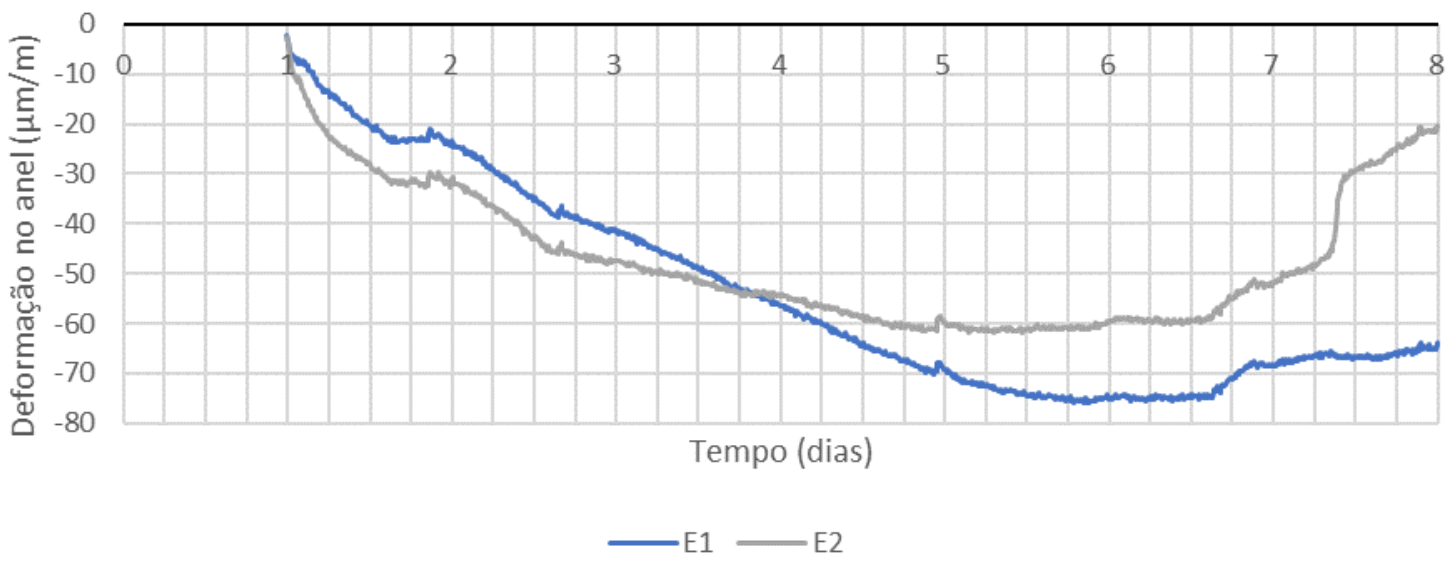

Figura 9: Deformação do anel de aço para o concreto $0,5 \mathrm{R}$.

O extensômetro E1 apresentou comportamento semelhante ao extensômetro do concreto 0,25P apresentado na Figura 7, e conforme descrito por Shah e Weiss [24], podem ser visualizados dois saltos, um mais e um menos substancial. Como descrito anteriormente, considerou-se o momento de fissuração como o início do alívio da tensão exercida pelo concreto no anel de aço, aproximadamente 157,83 horas após a moldagem, nesse caso 6,6 dias aproximadamente.

Na Tabela 6 estão dispostos os valores médios encontrados no ensaio de retração. Devido à pouca diferença entre eles, preferiu-se realizar a média em horas para posteriormente transformar para dias e então apresentar os resultados de acordo com a ASTM C1581-16. A ASTM C1581-16 [18] recomenda que a idade de fissuração, idade medida desde a moldagem do anel até o momento que ocorre uma redução repentina na deformação, seja expressa pelo 0,25 dia mais próximo. Dividindo-se o dia da fissuração em quatro partes o resultado foi um desses quatros valores que a idade obtida mais se aproximou.

Tabela 6: Valores médios de idade da fissuração ocorrida nos concretos.

\begin{tabular}{l|l|l|l|l|l|l}
\hline CONCRETO & $\mathbf{R E F}$ & $\mathbf{0 , 2 5 S}$ & $\mathbf{0 , 2 5 R}$ & $\mathbf{0 , 2 5 P}$ & $\mathbf{0 , 5 S}$ & $\mathbf{0 , 5 R}$ \\
\hline Ensaio 1 (horas) & 143,00 & 107,50 & 105,00 & 86,33 & 164,33 & 157,83 \\
\hline Ensaio 2 (horas) & 145,33 & 78,00 & - & 99,00 & 184,00 & 152,16 \\
\hline Média (horas) & 144,17 & 92,75 & 105,00 & 92,67 & 174,17 & 155,00 \\
\hline Resultado (dias) & 6,01 & 3,86 & 4,38 & 3,86 & 7,26 & 6,46 \\
\hline $\begin{array}{l}\text { Resultado - ASTM } \\
\text { C1581-16 (dias) }\end{array}$ & 6,00 & 3,75 & $4,25^{*}$ & 3,75 & 7,25 & 6,50 \\
\hline
\end{tabular}

* Valor obtido em apenas um ensaio

Os resultados dos ensaios apresentaram variações, em geral, pequenas para um mesmo tipo de concreto, chegando a 29,5 horas de diferença para o concreto $0,25 \mathrm{~S}$, valor dentro do desvio citado pela ASTM C1581-16 [18], que são 48 horas (dois dias) para uma mesma amostra. Observa-se que a adição de 0,25 \% de fibras apresentou comportamento inferior ao concreto sem adição de fibras. Destaca-se, portanto, que o teor de fibras utilizado comercialmente (geralmente inferior ao $0,25 \%$ utilizado nessa pesquisa) pode não estar sendo adequado, se o objetivo for a redução da fissuração do concreto por retração.

Outra característica é a semelhança entre os resultados obtidos para a fibra de polipropileno e as fibras vegetais quando em teor de $0,25 \%$. O concreto com adição de $0,5 \%$ de fibras demostrou melhor desempenho quando comparado ao concreto sem adição de fibras, com destaque para o concreto $0,5 \mathrm{~S}$ que apresentou a maior idade de fissuração.

Senisse [25] também estudou a influência da adição de fibras de polipropileno em concretos na retração por secagem restringida e concluiu que a adição de $450 \mathrm{~g} / \mathrm{m}^{3}$ não reduziu a tendência à fissuração para concretos com consumo de 190 1/m³ e 205 1/m³ de água, porém essa adição de fibras para concretos com consumo de água de $175 \mathrm{l} / \mathrm{m}^{3}$ demostrou-se adequada. Logo a tendência à fissuração em concretos com fibra de 
polipropileno é dependente do proporcionamento dos materiais que constituem o traço do concreto, sendo que a quantidade de fibras adicionada à mistura não é um valor fixo como tem sido empregado pelas empresas que utilizam concreto com adição desse tipo de fibra [25].

Os concretos foram mantidos até cerca de 20 dias após a moldagem nos anéis, na idade de 19 dias foram realizadas as medições das fissuras com fissurômetro, porém não foi possível estabelecer uma relação da dimensão da fissura com o tipo e teor de fibra, uma vez que essas fissuras eram bastante variáveis tanto quando comparadas aos mesmos tipos de concretos, como em seu próprio comprimento. Essas variações observadas demonstram que a abertura de fissuras depende da forma de dispersão da fibra na matriz, uma vez que é dispersa randomicamente é difícil uma padronização do comportamento desse concreto.

\subsection{Propriedades mecânicas}

Os resultados médios de todas as propriedades mecânicas avaliadas e o desvio padrão constam na Tabela 7.

Tabela 7: Resultados médios das propriedades mecânicas dos concretos estudados.

\begin{tabular}{l|l|l|l|l|l|l}
\hline \multirow{2}{*}{ TRAÇO } & \multicolumn{2}{l}{$\begin{array}{l}\text { COMPRESSÃO - 28 DIAS } \\
\text { (MPa) }\end{array}$} & \multicolumn{2}{l|}{$\begin{array}{l}\text { MÓDULO DE ELASTICI- } \\
\text { DADE (GPa) }\end{array}$} & \multicolumn{2}{l}{ TRAÇÃO (MPa) } \\
\cline { 2 - 7 } & Média & Desv.Padrão & Média & Desv.Padrão & Média & Desv.Padrão \\
\hline Ref & 36,22 & 3,51 & 32,77 & 3,30 & 3,53 & 0,03 \\
\hline $0,25 \mathrm{~S}$ & 32,81 & 3,97 & 31,03 & 4,39 & 3,17 & 0,11 \\
\hline $0,25 \mathrm{R}$ & 33,94 & 1,00 & 29,00 & 2,82 & 3,14 & 0,06 \\
\hline $0,25 \mathrm{P}$ & 36,89 & 2,34 & 30,40 & 3,42 & 3,15 & 0,03 \\
\hline $0,5 \mathrm{~S}$ & 34,11 & 3,90 & 31,60 & 1,25 & 3,36 & 0,24 \\
\hline $0,5 \mathrm{R}$ & 27,27 & 4,10 & 27,33 & 1,89 & 2,80 & 0,08 \\
\hline
\end{tabular}

Em relação à resistência à compressão aos 28 dias, houve pequena variação em relação à referência. A diminuição na resistência pode ser verificada principalmente no concreto $0,5 \mathrm{R}$ chegando a $24,7 \%$ de redução da resistência em relação ao concreto de referência. Essa redução pode ser explicada pela baixa fluidez apresentada pela mistura, o que provocou o adensamento ineficiente dos corpos de prova, além da formação de "ninhos" de fibra de rami. Contrariamente ao concreto $0,5 \mathrm{R}$, foi registrado para o concreto $0,5 \mathrm{~S}$ uma redução de apenas 5,83\% em relação ao concreto de referência. Essa pequena redução pode ser justificada pela melhor distribuição da fibra na matriz.

Já haviam sido avaliados por Al-Tayyib et al. [26] concretos com adição de $0,2 \%$ e sem adição de fibras de polipropileno, foi constatado que a fibra de polipropileno não provocou aumento na resistência a compressão. Quando avaliadas as resistências dos concretos com fibras vegetais tem-se, em geral, uma redução na resistência à compressão. Esse comportamento pode ser relacionado à maior dificuldade de adensamento e moldagem dos corpos de prova.

Em relação ao módulo de elasticidade a adição de fibras, em geral, provocou uma redução dessa propriedade, sendo que, mais uma vez destacou-se o concreto $0,5 \mathrm{R}$ com redução de $16,60 \%$ quando comparado ao concreto de referência, provavelmente devido às dificuldades na produção e moldagem. Os demais concretos com fibras apresentaram reduções menos significativas (abaixo de 11,5\%)

Dantas e Agopyan [27] encontraram um valor de módulo de elasticidade para o concreto com 0,25\% de polipropileno $18,45 \%$ superior quando comparado ao de referência. No trabalho citado anteriormente o desempenho superior pode ser devido a maior relação água/cimento (maior que um), em que a ação das fibras em uma matriz de baixa resistência pode ser mais expressiva. Resende [28] descreveu uma redução de $9,29 \%$ quando adicionado $1 \%$ de fibra de polipropileno no concreto de referência e adicionando o mesmo teor de fibra sisal, a redução foi de $5,36 \%$.

À semelhança do desempenho sob compressão, a adição das fibras vegetais provocou uma redução na resistência à tração do concreto, inclusive no concreto $0,25 \mathrm{P}$. A resistência para os concretos com $0,25 \%$ de fibra não apresentou grande diferença quanto ao tipo de fibra utilizado. $O$ melhor desempenho foi apresentado pelo concreto $0,5 \mathrm{~S}$ com redução de apenas $4,82 \%$ em relação ao de referência, enquanto o pior desempenho foi apresentado pelo concreto $0,5 \mathrm{R}$, provavelmente pelos motivos descritos anteriormente, com decréscimo de $20,68 \%$ quando comparado ao concreto sem fibra. 
Resende [28] analisou a resistência à tração na flexão em concretos com adição de 1,0 \% de fibras de polipropileno com $30 \mathrm{~mm}$ de comprimento. De acordo com o autor essa adição não modificou a resistência à tração em relação à matriz (concreto sem fibra) na fissuração, entretanto permitiu que na etapa pós fissuração a matriz continuasse a resistir aos mesmos níveis de tensão para valores de flecha significativos. Ainda de acordo com o mesmo autor ao estudar a resistência a tração na flexão de prismas com adição de $1 \%$ de fibra de sisal com $30 \mathrm{~mm}$ de comprimento foi constatado uma redução no valor em relação ao concreto de referência, uma das justificativas para essa redução é a menor trabalhabilidade do concreto com adição de fibra de sisal. Na ruptura dos concretos, foi observada maior deformação dos concretos com adição de fibras em relação ao concreto de referência. As divergências encontradas em outros estudos podem ser justificadas, dentre vários fatores, pelo procedimento adotados para o preparo e moldagem do corpo de prova, assim como os materiais utilizados.

\subsection{Absorção por imersão, índice de vazios, massa específica}

Os ensaios para a determinação da massa específica, absorção por imersão e índice de vazios foram realizados aos 28 dias. Os resultados obtidos são descritos na Tabela 8.

Tabela 8: Resultados médios da massa específica, absorção por imersão e índice de vazios dos concretos estudados.

\begin{tabular}{l|l|l|l}
\hline TRAÇO & ABSORÇÃO (\%) & ÍNDICE DE VAZIOS (\%) & MASSA ESPECÍFICA (g/cm $\left.{ }^{3}\right)$ \\
\hline Ref & 7,22 & 16,03 & 2,22 \\
\hline $0,25 \mathrm{~S}$ & 7,94 & 17,61 & 2,22 \\
\hline $0,25 \mathrm{R}$ & 10,24 & 21,89 & 2,14 \\
\hline $0,25 \mathrm{P}$ & 6,46 & 14,26 & 2,21 \\
\hline $0,5 \mathrm{~S}$ & 9,14 & 20,05 & 2,19 \\
\hline $0,5 \mathrm{R}$ & 9,85 & 21,28 & 2,16 \\
\hline
\end{tabular}

Observando a Tabela 8 pode-se notar que a massa específica, em geral, apresentou pequena variação com a adição de fibras, ao contrário da absorção que apresentou variação de mais de $40 \%$.

Com a adição de fibras no concreto tem-se uma tendência em aumentar a incorporação de ar durante a mistura, aumentando consequentemente a absorção e a porosidade. Entretanto, a absorção no concreto $0,25 \mathrm{P}$ apresentou um decréscimo de $10,53 \%$ em relação ao concreto de referência. Esse fato pode ser explicado pela redução do índice de vazios do compósito, contrário ao comportamento dos compósitos com fibra vegetal. Savastano Jr. [16] descreve que as fibras vegetais apresentam absorção de água superior à $90 \%$, essa alta absorção faz com que um forte fluxo de água seja induzido em direção à fibra. Ainda de acordo com o mesmo autor, esse fluxo de água acarreta em um aumento localizado da relação água/cimento, dando origem à elevada porosidade na zona de transição cuja espessura varia de $50 \mu \mathrm{m}$ a $100 \mu \mathrm{m}$. Isso não ocorre para o concreto com polipropileno, de acordo com Savastano Jr. [16] a porosidade na zona de transição para a fibra polipropileno não se apresenta muito elevada além da fibra quase não apresentar sinais de descolamento, pelo fato de não sofrer variações dimensionais no interior da matriz.

Para os concretos $0,25 \mathrm{~S}$ e $0,5 \mathrm{~S}$ o aumento da absorção foi da ordem de $10 \%$ e $26,59 \%$, respectivamente, em relação a absorção do concreto de referência. $\mathrm{O}$ aumento de $41,83 \%$ na absorção para o concreto $0,25 \mathrm{R}$ pode ser explicado pela alta taxa de exsudação apresentada por este concreto, resultando em um concreto mais poroso principalmente nas proximidades da fibra. Esse fato justifica inclusive o menor acréscimo na absorção do concreto com maior teor de fibra de rami, 0,50R que mesmo sendo um concreto com menor trabalhabilidade, apresentou um aumento de $36,43 \%$ da absorção.

Velasco [29] em seu estudo com concretos de alto desempenho constatou que a adição de 0,25\% de fibras de polipropileno não ocasionou mudanças significativas na porosidade e na densidade, um decréscimo de cerca de $2,72 \%$ e de $1,38 \%$ respectivamente. E a adição de $0,25 \%$ de fibra de sisal ocasionou acréscimos de $3,63 \%$ para a porosidade e $2,34 \%$ para a densidade. A divergência nos resultados encontrados deve-se, dentre vários motivos, ao tipo e quantidade de materiais utilizados além da forma de compactação dos corpos de prova. No trabalho de Velasco [29] foram utilizados vibradores externos (mesa vibratória) e vibradores internos (vibradores elétricos) além do adensamento ter sido realizado em três camadas. 


\subsection{Absorção por capilaridade}

O ensaio para avaliação da absorção por capilaridade foi realizado aos 70 dias, os valores de absorção de água por capilaridade (C) obtidos após 3, 6, 24, 48 e 72 horas de imersão parcial encontram-se no gráfico da Figura 10 relacionando a absorção por capilaridade com o tempo de imersão parcial.

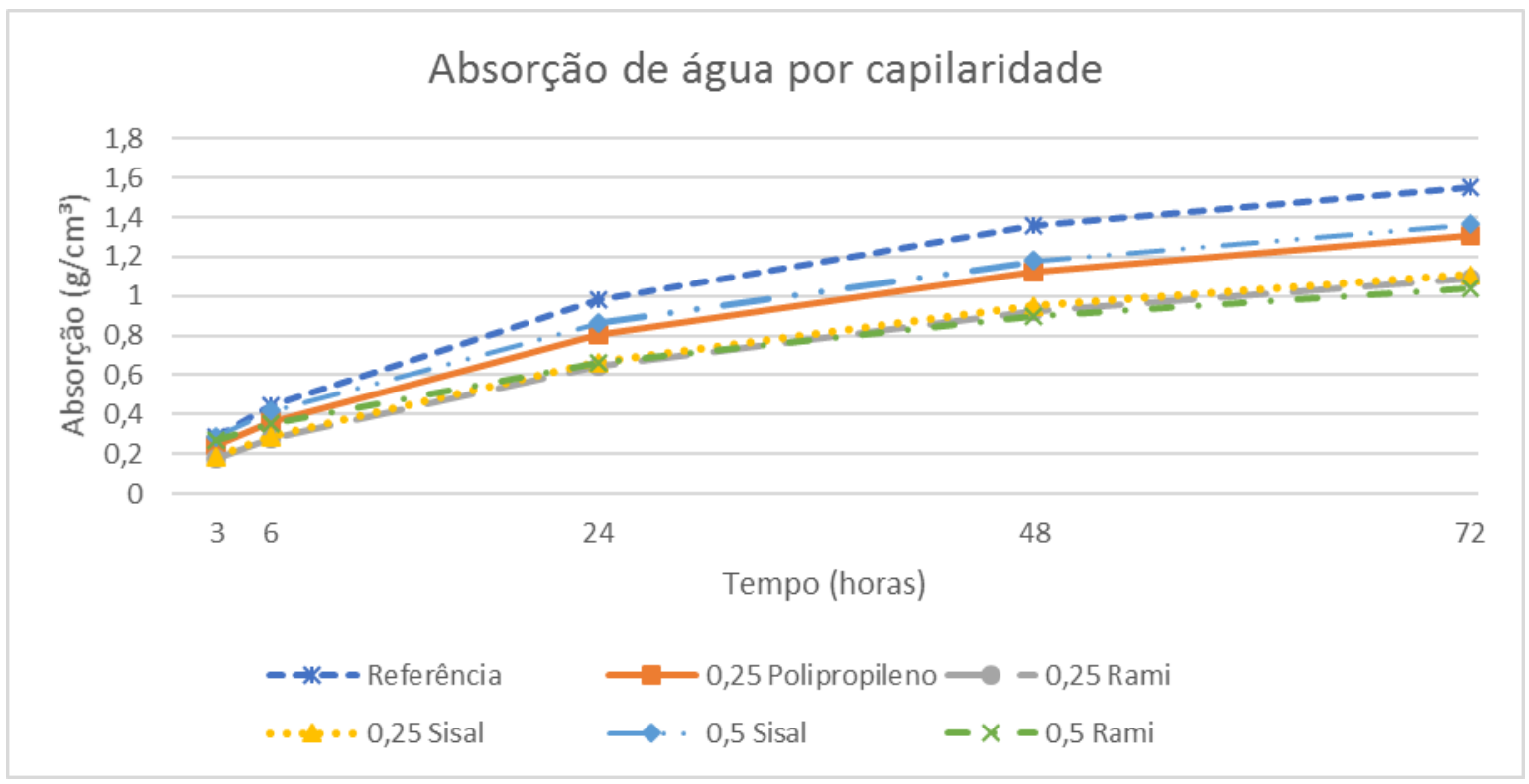

Figura 10: Absorção de água por capilaridade nos concretos estudados.

Contrário ao que foi constatado no ensaio de absorção por imersão, o concreto com maior absorção de água por capilaridade foi o concreto de referência e um dos concretos com menor absorção de água por capilaridade foi o 0,25R. Observa-se de acordo com o gráfico uma tendência das fibras, principalmente em teores menores, provocarem uma diminuição da absorção capilar. Avaliando a absorção 72 horas após a imersão parcial em água os compósitos 0,25S e 0,25R apresentaram uma absorção capilar aproximadamente $29 \%$ menor em relação ao concreto de referência. Os compósitos $0,25 \mathrm{P}$ e $0,5 \mathrm{~S}$ apresentaram menor redução, $16,13 \%$ e $12,26 \%$, respectivamente. O concreto $0,5 \mathrm{R}$ apresentou absorção capilar $32,90 \%$ menor em relação ao concreto de referência.

Quanto menor o diâmetro dos poros capilares, maiores serão as pressões capilares desenvolvidas e consequentemente maior a profundidade de concreto atingida pela água absorvida [30]. Em contrapartida quanto maior o diâmetro desses poros capilares menor a profundidade, porém maior a quantidade de água absorvida, contudo, um item de maior importância que o diâmetro desses capilares é a interconectividade entre eles [30]. A presença das fibras pode ter aumentado a porosidade e a absorção total dos compósitos, mas pode também ter reduzido a interconexão entre esses poros, inclusive por redução das microfissuras na matriz, reduzindo-se assim a absorção por capilaridade. Ressalta-se que esta redução da absorção capilar apresentada pelos concretos com fibras é importante quando estes são aplicados em paredes estruturais.

\section{CONCLUSÕES}

Em geral, os concretos com fibras apresentaram propriedades mecânicas inferiores ao concreto referência, porém não apresentaram grandes variações. A exceção do concreto $0,5 \mathrm{R}$ que conforme explicado anteriormente devido à baixa trabalhabilidade e a dispersão deficiente das fibras, apresentou resultados menores aos apresentados por todos os outros concretos estudados.

A absorção por imersão e índice de vazios, apresentaram aumentos com a adição de fibras vegetais, principalmente o concreto $0,25 \mathrm{R}$ que apresentou aumento da absorção de $40 \%$ em relação ao concreto de referência. $\mathrm{O}$ melhor desempenho nessas propriedades foi obtido com o concreto $0,25 \mathrm{P}$ que apresentou uma redução em relação ao concreto de referência, provavelmente devido comportamento hidrofóbico da fibra.

Todos os concretos com fibras apresentaram redução da absorção por capilaridade, provavelmente devido à tendência das fibras, principalmente em maiores teores, de impedir a intercomunicação entre os poros presentes no concreto, impedindo o aumento da altura de ascensão capilar. 
A utilização do ensaio do anel demostrou que os concretos com $0,5 \%$ de fibras apresentaram os melhores resultados. Entretanto para altos teores de fibras $(0,5 \%$ neste caso) se tem uma dificuldade na determinação da idade da ocorrência da fissuração, devido ao efeito "costura" gerado pelas fibras que atravessam as fissuras.

Ainda em relação aos resultados obtidos na retração restringida, devem ser realizados mais ensaios a fim de se comprovar que a adição de teores menores que $0,25 \%$ de fibras implicam na redução da resistência à fissuração do concreto, uma vez que muitas empresas têm adicionado teores de fibras inferiores com o intuito de reduzir a fissuração no concreto.

Assim, pelas proximidades dos resultados obtidos com a adição da fibra vegetal e de polipropileno, principalmente quando comparada com a fibra de sisal, é possível a substituição dessa fibra sintética e o emprego das fibras vegetais. Porém primeiramente deve-se comprovar a eficiência da adição de ambos os tipos de fibras principalmente em relação à diminuição da retração, que tem se mostrado a propriedade mais visada com a adição de polipropileno.

\section{AGRADECIMENTOS}

À BASF® pela doação do aditivo e à Brasmix ${ }^{\circledR}$ pela doação da fibra de polipropileno.

\section{BIBLIOGRAFIA}

[1] OLIVEIRA, L. A. de. Tecnologia de painéis pré-fabricados arquitetônicos de concreto para emprego em fachadas de edifícios. Dissertação de M.Sc., Escola Politécnica da Universidade de São Paulo, São Pau10,2002 .

[2] LORDSLEEM Jr., A. C. "O processo de produção das paredes maciças”. In: Seminário Tecnologia e Gestão na Produção de Edifícios Vedações Verticais - Tecnologia e Gestão na Produção de Edifícios. Escola Politécnica da Universidade de São Paulo, Departamento de Engenharia de Construção Civil. São Paulo, 1998.

[3] COLETÂNEA de ativos - Paredes de concreto 2011 - 2013. [S.I.]: Comunidade da Construção, 2013.

[4] BENTUR A., MINDESS S. Fibre reinforced cementitious composites. $2^{a}$ edição. Grã-Bretanha: Taylor \& Francis, 2007.

[5] SILVA, F. A. Durabilidade e propriedades mecânicas de compósitos cimentícios reforçados por fibras de sisal. Tese de D. Sc., Universidade Federal do Rio de Janeiro, Rio de Janeiro, 2009.

[6] LEVY NETO, F., PARDINI, L. C. Compósitos estruturais: ciência e tecnologia. $1^{\text {a }}$ edição. São Paulo, Blucher, 2006.

[7] SAVASTANO Jr., H. Fibras vegetais para construção civil: a fibra de coco, Boletim Técnico da Escola Politécnica da Universidade de São Paulo, São Paulo, 1986.

[8] SOUSA, L. K. Produção e caracterização mecânica de compósitos de resina poliuretana à base de óleo de mamona e fibras de rami, sisal e bucha vegetal, Dissertação de M.Sc., Universidade Federal de Uberlândia, Uberlândia, 2013.

[9] PONCIANO, C. A., VIEIRA, J. G., MOTTA, L. A. C., et al., "Estudo do uso da terra diatomácea residual como pozolana para incremento da durabilidade de compósitos reforçados com fibras de sisal", In: IV Encontro Nacional Sobre Aproveitamento de Resíduos na Construção Civil (ENARC), São Paulo, agosto, 2015.

[10] SOARES, I. M. Produção e caracterização de compósitos de matriz epóxi reforçada com fibra de rami para fins de reforço estrutural, Dissertação de M.Sc., Universidade Federal de Uberlândia, Uberlândia, 2012. [11] MACAFERRI. FibroMac 12. Fibras para reforço do concreto. Características técnicas. 2008.

[12] ASSOCIAÇÃO BRASILEIRA DE NORMAS TÉCNICAS, NBR NM 52, Agregado miúdo - determinação da massa específica e da massa específica aparente, Rio de Janeiro, 2009.

[13] ASSOCIAÇÃO BRASILEIRA DE NORMAS TÉCNICAS, NBR NM 53, Agregado graúdo - Determinação de massa específica, massa específica aparente e absorção de água, Rio de Janeiro, 2009.

[14] ASSOCIAÇÃO BRASILEIRA DE NORMAS TÉCNICAS, NBR NM 248, Agregado miúdo - determinação da composição granulométrica, Rio de Janeiro, 2009.

[15] BASF. Ficha técnica de produto. Glenium 3400NV Aditivo hiperplastificante. São Paulo, [s.d.]. 
[16] SAVASTANO Jr., H. Zona de transição entre fibras e pasta de cimento Portland: Caracterização e interrelação com as propriedades mecânicas do compósito, Tese de D. Sc., Escola Politécnica da Universidade de São Paulo, São Paulo, 1992.

[17] MEHTA, P. K., MONTEIRO, P. J. M. Concreto: Microestrutura, Propriedades e Materiais. $3^{a}$ Edição, São Paulo: IBRACON, 2008.

[18] AMERICAN SOCIETY FOR TESTING AND MATERIALS, ASTM C1581 / C1581M-16, Standard Test Method for Determining Age at Cracking and Induced Tensile Stress Characteristics of Mortar and Concrete under Restrained Shrinkage, ASTM International, West Conshohocken, PA, 2016.

[19] ASSOCIAÇÃO BRASILEIRA DE NORMAS TÉCNICAS, NBR 5739, Concreto - Ensaios de compressão de corpos-de-prova cilíndricos. Rio de Janeiro, 2007.

[20] ASSOCIAÇÃO BRASILEIRA DE NORMAS TÉCNICAS, NBR 8522, Concreto - Determinação do módulo estático de elasticidade à compressão. Rio de Janeiro, 2008.

[21] ASSOCIAÇÃO BRASILEIRA DE NORMAS TÉCNICAS, NBR 7222, Concreto e argamassa - Determinação da resistência à tração por compressão diametral de corpos de prova cilíndricos. Rio de Janeiro, 2011.

[22] ASSOCIAÇÃO BRASILEIRA DE NORMAS TÉCNICAS, NBR 9778, Argamassa e concreto endurecidos - Determinação da absorção de água, índice de vazios e massa específica. Rio de Janeiro, 2005.

[23] ASSOCIAÇÃO BRASILEIRA DE NORMAS TÉCNICAS, NBR 9779, Argamassa e concreto endurecidos - Determinação da absorção de água por capilaridade. Rio de Janeiro, 2012.

[24] SHAH, H. R., WEISS, J. "Quantifying shrinkage cracking in fiber reinforced concrete using the ring test", Materials and structures, v. 39, n. 9, p. 887-899, 2006.

[25] SENISSE, J. A. de L. Influência do consumo de água, do teor de adição de microfibras de polipropileno, e do tipo de cimento no fenômeno da retração por secagem em concretos empregados em pisos, Dissertação de M.Sc., Universidade Federal do Rio Grande do Sul, Porto Alegre, 2010.

[26] AL-TAYYIB, A. J., AL-ZAHRANI, M. M., RASHEEDUZZAFAR, et al., "Effect of polypropylene fiber reinforcement on the properties of fresh and hardened concrete in the Arabian Gulf Environment", $\mathrm{Ce}$ ment and Concrete Research, v. 18, p. 561-570, 1988.

[27] DANTAS, F. A. S., AGOPYAN, V. Análise da fissuração devida à retração. Boletim Técnico da Escola Politécnica da Universidade de São Paulo, São Paulo, 1988.

[28] RESENDE, F. M. Influência das fibras de aço, polipropileno e sisal no amortecimento de concretos de alta resistência normal e de alto desempenho. Dissertação de M.Sc., Universidade Federal do Rio de janeiro, Rio de Janeiro, 2003.

[29] VELASCO, R. V. Concreto de alto desempenho reforçado com fibras de polipropileno e sisal submetido a altas temperaturas, Dissertação de M.Sc., Universidade Federal Do Rio De Janeiro, Rio de Janeiro, 2002.

[30] HELENE, P. R. do L. Contribuição ao estudo da corrosão em armaduras de concreto armado, Tese (Livre-Docência, Escola Politécnica da Universidade de São Paulo, São Paulo, 1993.

\section{ORCID}

Leila Aparecida de Castro Motta

Ana Paula Silva Nascentes Borges

Eliane Bernardes Pinto https://orcid.org/0000-0002-1597-2297

https://orcid.org/0000-0002-1351-4604

https://orcid.org/0000-0002-3857-7601 